\title{
Foreign Exchange Program Trading: A Bilingual Teaching Design
}

\author{
Qingmei Tao \\ School of Finance, Chongqing Technology and Business University, Chongqing 400067, China \\ taoqingmei@ctbu.edu.cn
}

Keywords: program trading, bilingual teaching, curriculum construction, experimental design, teaching quality evaluation

Abstract: Program trading is more and more frequently applied in foreign exchange trading, thus there are high demand for professional trader in foreign exchange program trading. To meet the need of job market, the bilingual teaching in high education institutions has been well developed in teaching fields such as economics, finance and foreign exchange market theories. But bilingual teaching in foreign exchange market field has focused mainly on theoretical part in most high education institutions. This paper tries to extend the theories into practice. It first introduces the current situation of program trading usage in financial market; secondly, it gives a framework on program trading application in foreign exchange trading; it then designs a basic experimental teaching for students to apply the program trading in foreign exchange market; it ends with teaching quality evaluation. The whole design is based on but not limited to TradeStation.

\section{Introduction}

Foreign exchange market is the biggest market in terms of trade volume and is one of the fastest growing segments in the financial world. Trading in foreign exchange markets averaged \$5.1 trillion per day in April 2016 according to IBS and this number has been growing because of the application of computer science and informational technology. The trade facilities such as electronic trading platforms, procedural transaction, brokering systems have stimulated more innovative trading methods, among which program trading is developing into a significant force in foreign exchange market.

China Securities Regulatory Commission defined program trading as a type of trading in securities, usually consisting of a basket of stocks that are executed by a computer program simultaneously based on predetermined conditions. In general, program trading is a progress through the computer and internet to execute one set of programs. Based on computer platform, trading models and internet, program trading includes algorithm trading, high frequency trading and basket trading. Because that program trading integrates the dealers trading strategy into machine learning, it may cause violent volatility in financial market. Ever since the Everbright Securities 
Company trading error on 16th Aug. 2013, regulation on program trading has been strengthened. Because of the sovereignty issue when involving two currencies, foreign exchange market has little (if any) supervisory entity regulating its actions. Program trading is more and more frequently applied in daily foreign exchange trading, thus there are high demand for professional trader in foreign exchange program trading.

To meet the need of job market, the bilingual teaching in high education institutions has been well developed in teaching fields such as economics, finance and foreign exchange market theories. But teaching in foreign exchange market field has focused mainly on theoretical part in most high education institutions. Considering the high demand on traders in foreign exchange program trading, it is necessary to extend the teaching in foreign exchange into more practical topic: the program trading in foreign exchange market.

\section{Teaching Goals}

\subsection{Target Students}

This course is designed for the undergraduate students, 3rd year, major in finance. More specifically, it is suitable for students that plan to study abroad or intend to have further understanding of foreign exchange trading in practice field. Other foreign exchange traders or financial market participants may find this course useful.

\subsection{Course Goals}

The main goal of this course is to teach undergraduate students understand the program trading methods by applying a specific software, TradeStation. The subject of trading could be foreign exchange, stock, bonds, and other financial products. By giving lectures on the above said contents, students are required to use TradeStation for program trading design, which should integrate diverse investment strategies, so that students be cultivate innovation and theory application. Considering the dominant trend of program trading in developed countries' financial market, this course helps China's student to fit in the futures job requirement.

Through the course learning, students build the ability to recognize the pros and cons of program trading, is able to apply basic trading strategy into foreign exchange trade and can produce fundamental coding for basic foreign exchange trading.

\subsection{Grading Policies}

Considering program trading requires a lot practices in foreign exchange field, this course is assessed by 3 parts: final examination (weight 30\%), daily performance (weight 30\%) and experimental performance (weight 40\%). In order to educate students practical application, more weight is granted to experimental performance that provides the application of program trading during the semester.

Final examination is composed by 5 parts: multiple choices, true or false, short answer question, numerical work, comprehensive analysis.

At the very beginning of this course, each student is assigned 50 points as their daily performance fund. The homework is optional. Students may choose to work on homework which may earn them extra credits to their daily performance. Other ways to earn credits are: class participation, suggestion to teaching, notes and presentations. Course attendance is essential. Each absence costs 5 points in their daily performance fund. 
Experimental performance is assessed by two ways: experimental report and program coding.

\section{Syllabus}

As a contract between teachers and students, syllabus sets the stage for learning throughout the course. Hard copies of syllabus of Program Trading will be handed out to students at the very beginning of semester and the digital syllabus be posted on the course website.

\subsection{Course Description}

This course is designed as a supplementary for bilingual course Foreign Exchange Theory and Market. It provides an overview of the program trading in foreign exchange market. It gives an overview of operations of foreign exchange market, introduces basic models for exchange rate determination, and offers the fundamental application of software usage.

This course contains practical operation in foreign exchange markets, including cash market, spot market, forward market, currency futures market, foreign exchange swap and foreign exchange options market. Also, it applies fundamental theories into trading practice, theories include exchange rate determination, foreign exchange speculation and hedging methods, foreign exchange rate forecasting techniques, foreign exchange exposure and risk management. The field of this course, however, covers not only the foreign exchange market but also other financial derivatives market. Program trading is actually widely used all across the financial market.

\subsection{Exercises and Homework Grading System}

Grading will be based on a curve with guidance by the following percentage of total points:

\begin{tabular}{|c|c|c|c|c|c|c|}
\hline level & percentage & grading & percentage & grading & percentage & grading \\
\hline $\boldsymbol{A}$ & $\mathbf{9 0 - 9 3 \%}$ & $\boldsymbol{A}-$ & $94-100 \%$ & $\mathrm{~A}$ & $\mathrm{~N} / \mathrm{A}$ & $\mathrm{N} / \mathrm{A}$ \\
\hline $\boldsymbol{B}$ & $\mathbf{8 0 - 8 2 \%}$ & $\boldsymbol{B}-$ & $83-86 \%$ & $\mathrm{~B}$ & $87-89 \%$ & $\mathrm{~B}+$ \\
\hline $\boldsymbol{C}$ & $\mathbf{7 0 - 7 2 \%}$ & $\boldsymbol{C}-$ & $73-76 \%$ & $\mathrm{C}$ & $77-79 \%$ & $\mathrm{C}+$ \\
\hline $\boldsymbol{D}$ & $\mathbf{6 0 - 6 2 \%}$ & $\boldsymbol{D}-$ & $63-66 \%$ & $\mathrm{D}$ & $67-69 \%$ & $\mathrm{D}+$ \\
\hline $\boldsymbol{E}$ & Below $\mathbf{6 0 \%}$ & $\boldsymbol{N} / \boldsymbol{A}$ & N/A & N/A & N/A & N/A \\
\hline
\end{tabular}

\subsection{Homework Requirement}

The intent of the homework is to gain a greater understanding of the materials, not only to enhance performance on the tests, but also to gain a greater foundation in the understanding of the foreign exchange program trading. Homework will be assigned after that content of the chapter is covered in class. Homework should be due at the beginning of the class period after the content is covered. Late homework will receive no credit. Students anticipating an absence may trust others to submit. Assigned homework should be handwriting (word processed homework will receive no credit.) or completed on software accompanying the TradeStation, MT4 or Excel. Students are encouraged to explore the learning potential of these software options. It is assumed most responses will be a minimum of half page. Considering high student-to-staff ratio in terms of bilingual teaching, homework points will be awarded only for effort. But a majority of test questions will be based on homework. Students are responsible for checking their own answers. Answers to homework will be emailed to students' representatives after the homework is due. Students are encouraged to bring questions about the homework to class. It is recommended that the students bring an extra copy of the problem to the class if they wish to take notes after asking questions. 


\section{Test and Final Examination}

The test is set in the middle of semester, it will cover material primarily from problems and exercises in homework. Additionally, some questions will be taken from reading materials. Final examination is a close-book cumulative and comprehensive test. It covers the following question type:

(1) Multiple choice question $(2 \times 10=20)$ is about basic definition and concepts.

(2) True or false question $(2 \times 10=20)$ mainly includes mistakes that are often found in foreign exchange program trading.

(3) Short answer question $(5 \times 4=20)$ for simple technologies of trading.

(4) Numerical question $(5 \times 4=20)$ for basic calculation of foreign exchange market.

(5) Comprehensive analysis $(10 \times 2=20)$ requires students read through the data and information, then write the solution.

\section{Experimental Teaching Design}

According to the above stated syllabus, every chapter of foreign exchange instrument provides experimental section. This is a crucial part of the course. Students must go through this section to obtain the necessary practical experience in program trading.

\subsection{Software and System for Foreign Exchange Program Trading}

There are many options to choose a software for foreign exchange program trading. Software that are frequently used in foreign exchange trading are OpenQuant, WH8, MultiCharts, ShareFX, OmegaTradestation, OminiTrader and StradeStation. To choose a proper software for teaching the foreign exchange program trade need to consider:

\subsubsection{Experimental Teaching requires demo account}

For teaching purpose, courses need great number of demo accounts to make sure each student is able to practise on. Some software associsting with real account is not suitable for teaching. It is common students may suffer great loss during their practise, demo account guarantees students capital safty while learning the trading.

\subsubsection{Software is economically feasible for teaching purpose}

During teaching, each student need open an account. This masive usage ask for low cost. Ideally, no administration fee for daily trading. Some software developer provides teaching version. This course will consider educational version of foeign exchange trade software.

\subsubsection{Fully functional}

Some software may provide teaching version for low price, but with a cost of very limited function.

Considering the above requirements, EasyLanguage program is one of the ideal software to achieve trading goals in Tradestation. Guosen Securities, a leading Chinese financial services firm with strong business pipelines, offers Tradestation for teaching purpose. As one of the top ranked firms for securities trading and stock listing offers in China, the software Guosen provides meet the teaching requirement. 


\subsection{Experimental Teaching Topics}

Experimental teaching is the supplement section of theoretical teaching. After the first two section of each chapter, proper experimental teaching is arranged. The following topics are suggested for experimental teaching design:

(1) Introduce the trading system and software;

(2) Program code for basic indicators such as support line, resistance line and trend line, etc.

(3) Analysis of the technical indicators such as MACD, CCI, KDJ

(4) Fair value calculation

(5) Set up buy/sell threshold and buy/sell active for taking long/short position program

(6) Basic trading strategies

(7) Application of trading strategies such as Aberration strategy, R-Breaker strategy, Dollar Trader strategy

\section{Acknowledgement}

This paper is supported and funded by Chongqing Technology and Business University (1751011).

\section{References}

[1] Board J, Sutcliffe C. Program Trading [M]// Wiley Encyclopedia of Management. John Wiley \& Sons, Ltd, 2015.

[2] J Santoni B G. Index Arbitrage and Stock Price Volatility [J]. Wall Street Journal, 1991.

[3] Jordan S J, Lee W B, Park J W. Program Trading and the Link Between the Spot and Futures Prices[J]. Journal of Futures Markets, 2015, 35(12):1133-1153.

[4] Moser J T. Do program trading cause stock prices to overreact? [J]. Federal Reserve Bank of Chicago, 1994, v18 (n4):19-24.

[5] Securities and Exchange Commission (1988): The October 1987 Market Break. Washington: US. Securities and Exchange Commission (SEC)

[6] U.S. Commodity Futures Trading Commission and the U.S. Securities and Exchange Commission, FINDINGS REGARDING THE MARKET EVENTS OF MAY 6, 2010 http://www.sec.gov/news/studies/2010/marketeventsreport.pdf. 